\title{
$\beta$-carotene and $\alpha$-tocopherol coencapsulated in nanostructured lipid carriers of murumuru (Astrocaryum murumuru) butter produced by phase inversion temperature method: characterisation, dynamic in vitro digestion and cell viability study
}

\author{
G. V. L. Gomes ${ }^{a}$, M. R. Sola ${ }^{a}$, A. L. Rochetti ${ }^{b}$, H. Fukumasu ${ }^{b}$, A. A. Vicente ${ }^{c}$ and S. C. Pinho ${ }^{a}$ \\ ${ }^{a}$ Department of Food Engineering, School of Animal Science and Food Engineering, University of São Paulo (USP), Pirassununga, \\ Brazil; bepartment of Veterinary Medicine, School of Animal Science and Food Engineering, University of São Paulo (USP), \\ Pirassununga, Brazil; 'CEB, Centre of Biological Engineering, University of Minho, Campus de Gualtar, Portugal
}

\begin{abstract}
Hydrophobic bioactives can be more easily incorporated into food and have their bioavailability enhanced if nanostructured lipid carriers (NLC) are used as carriers. In the present study, betacarotene-loaded NLC were produced by low emulsification using murumuru butter and a mixture of Span 80 and Cremophor RH40 as surfactants. Their average diameter was $35 \mathrm{~nm}$ and alpha-tocopherol was required to protect the encapsulated $\beta$-carotene. Besides the evaluation of their physicochemical stability, NLC were submitted to dynamic in vitro digestion and cell viability assays with Caco-2 and HEPG cells. The bioaccessibility of beta-carotene in the dynamic system was about $42 \%$. Regarding cell viability, results indicated NLC were toxic to the cell cultures tested. Such high toxicity is probably related to the type of surfactant used and to the extremely reduced particle size, which may have led to an intense and fast permeation of the NLC through the cells.
\end{abstract}

\section{ARTICLE HISTORY}

Received 1 October 2018

Accepted 14 February 2019

\section{KEYWORDS}

Phase inversion

temperature; solid lipid

nanoparticles; Astrocaryum

murumuru; beta-carotene;

bioaccessibility

\section{Introduction}

Beta-carotene is a bioactive of high interest for the food industry due to its biological activity related to its strong antioxidant characteristics (Fraser and Bramley 2004, Bertram and Vine 2005, Cao-Hoang et al. 2010). However, its application in food products can be still challenging, due to its high hydrophobicity, chemical instability, and lipophilicity, which also leads to low bioavailability during digestion (BritoOliveira et al. 2017). One possible approach to improve the stability and increase the bioavailability of the beta-carotene is its encapsulation in lipid-based matrices, as nanoemulsions and lipid nanoparticles.

Low energy emulsification methods have been more extensively investigated for food applications in the last five years (Pinho et al. 2018, Borrin et al. 2018, de Carli et al. 2018; Komaiko and McClements 2015). A reason for such increasing interest is the possibility of producing much smaller droplets than using traditional high energy emulsification methods are used (McClements and Rao 2011). Additionally, the energy density typical of low energy emulsification methods is in the range $10^{3}-10^{6} \mathrm{~W} / \mathrm{kg}$, much less than the typical value for high energy methods $\left(10^{8}-10^{10} \mathrm{~W} / \mathrm{kg}\right)$, which can be advantageous economically (Gupta et al. 2016).

Low energy methods can be subdivided into spontaneous emulsification and phase transition methods. Regarding phase inversion methods, there is the phase inversion temperature (PIT) method, first proposed by Shinoda and Saito (1968). It relies on the capacity of polyethoxylated non-ionic surfactants to be dehydrated during heating. Such dehydration changes their HLB (hydrophilic-lipophilic balance) values and, therefore, their affinity for each phase can be modified from hydrophobic (i.e. stabilisers of $\mathrm{O} / \mathrm{W}$ emulsions) to hydrophobic (i.e. stabilisers of W/O emulsions). At a specific temperature (called PIT temperature, or $\mathrm{T}_{\mathrm{PIT}}$ ), the emulsion can be inverted, and, if the system is cooled down fast enough, the surfactant becomes hydrophilic again and very small droplets can be produced (Anton and Vandamme 2009).

The PIT method can be used as well to produce solid lipid nanoparticles (SLN) (Montenegro et al. 2012,

CONTACT S. C. Pinho samantha@usp.br B Department of Food Engineering, College of Animal Science and Food Engineering, University of São Paulo (USP), Av. Duque de Caxias Norte 225 - Jd Elite, Pirassununga, SP 13635-900, Brazil

(C) 2019 Informa UK Limited, trading as Taylor \& Francis Group 
Gao and McClements 2016, Gomes et al. 2017). The use of mixtures of lipids to produce the core of SLN may be responsible for the formation of imperfect structures, amorphous lipid cores and also for minimising or avoiding the expulsion of the bioactive to the most external parts of the particle, protecting them from the action of the oxidant agents (Tikekar and Nitin 2011, Pan et al. 2016). Solid lipid nanoparticles with a disorganised lipid core are often also named nanostructured lipid carriers, or NLC (Müller et al 2000). Vegetable butters are interesting to be used as lipids for the production of NLC as they are, naturally, mixtures of several different types of triglycerides. Some vegetable butters are practically unexplored in the production of lipid nanoparticles, as murumuru (Astrocaryum murumuru) butter. This butter, obtained from an Amazon palm tree, is rich in medium-chain triglycerides (about $52 \%$ of the fatty acid composition is C8-C12 chains), and it is considered a lauric acid (Mambrim and Barrera-Arellano 1997).

The bioavailability of encapsulated bioactives in lipid nanocarriers has been extensively investigated in the literature, both using in vitro static and dynamic digestion protocols and models (Pinheiro et al. 2016, Gomes et al. 2017). Dynamic in vitro models try to simulate the digestion as a continuous process, with several compartments (mouth, stomach, and different parts of intestine), together with the peristaltic movements (Guerra et al. 2012). Among the most used dynamic in vitro digestion simulation systems is the TIM - TNO INTESTINAL MODEL, developed by TNO Nutrition and Food Research (Zeist, The Netherlands) (Guerra et al. 2012, Ménard et al. 2014). TIM is an in vitro dynamic system controlled by computational systems, which simulates in vivo conditions and kinetic events which occur in the human gastrointestinal tract. It is considered as very complete and allows a simulation very close to the dynamic events which occur in the stomach and small intestine (Guerra et al. 2012). These events include simulation of $\mathrm{pH}$ changes, temperature, peristaltic movements, enzymes, bile, and pancreatic juice secretion, as well as the absorption of digestion products by the small intestine mucosa (Reis et al. 2008).

Additionally, evaluation of cell toxicity is also important, as the unique physicochemical characteristics of nanomaterials and their high reactivity can reflect on their toxicity (Ciappellano et al. 2016). A common assay to evaluate cytotoxicity is the study of cell viability (Doktorovova et al. 2014), which consists of an in vitro cell culture approach (Loh et al. 2010).
This study aimed at encapsulating $\beta$-carotene in NLC produced with murumuru (A. murumuru) butter by the PIT method, and to characterise the nanodispersions during a storage period of 4 months. The most NLC formulations were submitted to a dynamic in vitro digestion system and had their cytotoxicity evaluated using Caco-2 and HEPG cell cultures.

\section{Materials and methods}

\section{Materials}

The lipid phase of the NLC was murumuru butter ( $A$. murumuru) (Jacy Fragrâncias, Santa Barbara D'Oeste, $\mathrm{SP}$, Brazil). The bioactive incorporated in NLC was $\beta$-carotene (Fluka, Seelze, Germany). Alpha-tocopherol (Sigma-Aldrich, St. Louis, MO) was added to some formulations. The surfactants used were 40PEG hydroxylated castor oil (Cremophor RH 40, BASF, Ludwigshafen, Germany) and sorbitan ester 80 (Span 80, Sigma-Aldrich, St. Louis, MO). All chemicals used in the experiments were reagent grade. All chemicals used in the in vitro digestibility experiments were obtained from Sigma-Aldrich (St. Louis, MO): pepsin from porcine gastric mucosa $(600 \mathrm{U} / \mathrm{mL})$, lipase from porcine pancreas $(40 \mathrm{U} / \mathrm{mL})$, pancreatin from porcine pancreas $(8 \times$ USP), bile extract porcine and the salts used for preparing the gastric and small intestinal electrolyte solutions, hydrochloric acid, and sodium bicarbonate. DeioniSed water (Direct Q3, Millipore, Billerica, MA) was used throughout the experiments.

\section{Production of the murumuru butter NLC by PIT method}

The NLC were produced according to the method described elsewhere (Gomes et al. 2017). The following masses were used to produce $100 \mathrm{~g}$ of nanodispersions: $10 \mathrm{~g}$ murumuru butter, $80 \mathrm{~g}$ deionised water, $8 \mathrm{~g}$ Span 80 and $12 \mathrm{~g}$ Cremophor RH 40. A hot dispersion of the surfactants (Cremophor $\mathrm{RH} 40$ and Span 80 ) was dispersed in the melted murumuru butter using mechanical stirring (500 rpm with Cowles impeller). Afterwards, the dispersion was submitted to two heating/cooling cycles. $\beta$-carotene $(0.06 \mathrm{~g} / 100 \mathrm{~g}$ dispersion of nanoparticles) and $\alpha$-tocopherol (when present, $0.03 \mathrm{~g} / 100 \mathrm{~g}$ dispersion of nanoparticles) were added to the dispersion before the second heating cycle. Variations of conductivity with temperature were obtained using a conductivimeter (Inolab 740, WTW, Weilheim, Germany). The phase inversion temperature $\left(T_{P I T}\right)$ was determined as the average of the onset of decrease in conductivity and the minimum 
temperature reached by the system after phase inversion (Gomes et al. 2017, Bovi et al. 2017). The system was heated to $80^{\circ} \mathrm{C}$ (at a rate of $10^{\circ} \mathrm{C} / \mathrm{min}$ ) and cooled down to $20^{\circ} \mathrm{C}$ (at a rate of $6^{\circ} \mathrm{C} / \mathrm{min}$ ).

\section{Determination of average particle size, particle size distribution, and polydispersity}

Mean hydrodynamic diameter, the particle size distribution, and the polydispersity of the NLC were determined using photon correlation spectroscopy in ZetaPlus equipment (Brookhaven Instruments Company, Holtsville, NY), at $25^{\circ} \mathrm{C}$, with the aid of the software included with the system (90Plus). Before analyses, the samples were diluted with ultra-pure water to prevent multiple light scattering.

\section{Quantification of encapsulated $\beta$-carotene}

$\beta$-carotene encapsulated in the NLC was quantified according to Cornacchia and Roos (2011) modified by Gomes et al. (2017). Firstly, the NLC sample was diluted $(100 \times)$ with ultrapure water. Afterwards, $1.5 \mathrm{ml}$ of ethanol and $1 \mathrm{ml}$ of methanol saturated with $\mathrm{KOH}$ were mixed with $2 \mathrm{ml}$ of the diluted sample. Then the mixture was heated to $45^{\circ} \mathrm{C}$ for $30 \mathrm{~min}$. The extraction of $\beta$-carotene occurred due to washing of the total volume of this mixture $(4.5 \mathrm{ml})$ three times with $2 \mathrm{ml}$ of $n$-hexane containing $0.1 \%(\mathrm{w} / \mathrm{v})$ butylated hydroxytoluene (BHT). The $n$-hexane was added to the dispersion, and then the mixture was stirred and left to stand for $10 \mathrm{~min}$. The organic layer containing $\beta$-carotene was removed with a glass pipette and its absorbance was measured at $450 \mathrm{~nm}$ using a spectrophotometer Libra 22S (Biochrom, Cambridge, UK).

\section{Quantification of encapsulated $\alpha$-tocopherol}

The extraction of $\alpha$-tocopherol from the NLC was conducted using the same protocol previously described for $\beta$-carotene extraction. The top layer obtained after washing contained also $\alpha$-tocopherol, which was analysed by spectrofluorometry (LS55, Perkin Elmer, Waltham, MA), using excitation and emission wavelengths of 290 and $327 \mathrm{~nm}$, respectively (Relkin and Shukat 2012).

\section{Transmission electron microscopy (TEM)}

The micrographs obtained by TEM were produced by an EM $902 \mathrm{~A}$ microscope (Zeiss, Jena, Germany) at an accelerating voltage of $80 \mathrm{kV}$. The samples were prepared by dropping the nanoemulsions onto copper grids coated with carbon film. Afterwards, they were stained with uranyl acetate and let to dry naturally.

\section{Dynamic in vitro digestion of murumuru butter NLC}

A dynamic in vitro digestion system was used to evaluate the digestibility of the NYC and also the bioaccessibility of encapsulated $\beta$-carotene. In both cases, the following gastric, duodenal, jejunal, and ileal fluids were prepared as following (Pinheiro et al. 2016, Gomes et al. 2017):

- Gastric fluid: pepsin and lipase in a gastric electrolyte solution $(2.2 \mathrm{~g} / \mathrm{L} \mathrm{KCl}, 1.5 \mathrm{~g} / \mathrm{L} \mathrm{NaHCO} 3,4.8 \mathrm{~g} / \mathrm{L}$ $\mathrm{NaCl}$ and $0.22 \mathrm{~g} / \mathrm{L} \mathrm{CaCl}_{2}$ )

- Duodenal fluid: $7 \%(\mathrm{w} / \mathrm{v})$ of pancreatin solution, $4 \%$ $(\mathrm{w} / \mathrm{v})$ of porcine bile extract and $20 \mathrm{~mL}$ of SIES (small intestinal electrolytic solution, produced with $5 \mathrm{~g} / \mathrm{L} \mathrm{NaCl}, 0.6 \mathrm{~g} / \mathrm{L} \mathrm{KCl}, 0.25 \mathrm{~g} / \mathrm{L} \mathrm{CaCl}_{2}$ ).

- Jejunal fluid: $10 \%(\mathrm{w} / \mathrm{v})$ of porcine bile extract and SIES.

- Ileal fluid: only SIES.

A TIM-like dynamic gastrointestinal system simulating stomach, duodenum, jejunum, and ileum steps was used. Each digestion step (compartment) was built using two connected glass chambers containing a flexible wall, and water was pumped around the flexible walls to enable the simulation of the peristaltic movements (by the alternate compression and relaxation), maintaining the temperature at $37^{\circ} \mathrm{C}$. The compartments were linked by silicone tubes and, at predefined periods, a constant volume of chyme was transferred. All compartments had their $\mathrm{pH}$ values controlled by the injection of $\mathrm{HCl}$ solution $(1 \mathrm{M})$ into the stomach and $\mathrm{NaHCO}_{3}$ solution (1 M) into the intestinal compartments. The gastric and intestinal fluids were added via syringe pumps at pre-set flow rates. The jejunum and ileum compartments were connected with hollow-fiber devices (M20S-100-01P, SpectrumLabs, Rancho Dominguez, CA) to simulate the absorption of digestion products and water from the chyme.

The digestion protocol started with the introduction of $40 \mathrm{ml}$ of NLC into the stomach compartment and the experiment run for $5 \mathrm{~h}$, simulating average physiological conditions of gastrointestinal tract by the continuous addition of simulated digestive fluids. The gastric fluid was injected at a flow rate of $0.33 \mathrm{ml} /$ $\min ^{-1}$ and the $\mathrm{pH}$ was controlled from $\mathrm{pH}=4.8$ at 
the beginning of the digestion to $\mathrm{pH}=1.7$ at $120 \mathrm{~min}$, by injecting $\mathrm{HCl}(1 \mathrm{M})$. Duodenal, jejunal, and ileal fluids were injected at a flow rate of $0.66 \mathrm{ml} / \mathrm{min}$; $2.13 \mathrm{ml} / \mathrm{min}$, and $2.0 \mathrm{ml} / \mathrm{min}$, respectively. The $\mathrm{pH}$ in the different parts of small intestine was controlled by the addition of $\mathrm{NaHCO}_{3} 1 \mathrm{M}$ to set-points of $6.5,6.8$, and 7.2 for simulated duodenum, jejunum, and ileum steps, respectively.

During in vitro digestion, samples were obtained directly from the lumen of the different compartments, from the jejunal and ileal filtrates and from the ileal delivery. Samples were analysed for zeta potential, average particle size, release of free fatty acid, and bioaccessibility of $\beta$-carotene.

\section{Quantification of free fatty acids release}

The release of free fatty acid during jejunum and ileal steps was measured by titration using $\mathrm{NaOH}(1 \mathrm{M})$. The volume of $\mathrm{NaOH}$ solution added to the digested NLC was used to obtain the free fatty acids concentration generated by lipolysis, according to the following equation (Bonnaire et al. 2008):

$$
\% F F A=100 \times\left(\frac{V_{\mathrm{NaOH}} \times M_{\mathrm{NaOH}} \times M M_{\text {lipid }}}{w_{\text {lipid }} \times 2}\right)
$$

where: \%FFA = percentage of released free fatty acids; $V_{\mathrm{NaOH}}=$ volume of sodium hydroxide used in the titration (in $\mathrm{mL}$ ); $M_{\mathrm{NaOH}}=$ molarity of $\mathrm{NaOH}$ solution; $M M_{\text {lipid }}=$ molecular mass of the reference lipid $\left(284.5 \mathrm{~g} / \mathrm{mol}\right.$ for stearic acid); $w_{\text {lipid }}=$ initial mass of lipid (in grams).

\section{Quantification of bioaccessible $\beta$-carotene}

A volume of the raw digesta was centrifuged at $4000 \mathrm{rpm}$ for $40 \mathrm{~min}$ (at $25^{\circ} \mathrm{C}$ ). Afterwards, the supernatant was collected ('micelle fraction,' in which the bioactive compound was 'solubilised'). This micelle phase was then carefully collected using a glass pipette. Volumes of aliquots of $5 \mathrm{ml}$ of samples (raw digesta or micelle fraction) were mixed with $5 \mathrm{ml}$ of chloroform, submitted to vortex and centrifuged at $1750 \mathrm{rpm}$ for $10 \mathrm{~min}$, at $25^{\circ} \mathrm{C}$. The bottom layer was collected, whereas the upper layer was mixed with $5 \mathrm{ml}$ of chloroform, and the same procedure was followed. The bottom chloroform layer was added to the first one collected, and the absorbance was determined at $450 \mathrm{~nm}$ (Libra S22, Biochrom, Cambridge, UK) (Salvia-Trujillo et al. 2013).

\section{Evaluation of Caco-2 and HEPG cells viability}

Caco-2 (human colon adenocarcinoma) and HEPG (human hepatoma) cells were obtained from Oswaldo Cruz Institute (Rio de Janeiro, RJ, Brazil). The cells were maintained in DMEM (Dulbeccós modified Eaglés minimal essential medium) supplemented with $1 \%$ antibiotics (pen-strep), and 2\% amino acids and foetal bovine foetal serum (20\% for Caco-2 and $10 \%$ for HEPG). The environmental conditions were $37^{\circ} \mathrm{C}$ in a humidified incubator with an atmosphere containing $7 \% \mathrm{CO}_{2}$. The supernatant of confluent cells was removed and cells were exposed to trypsin until complete detach and disaggregate completely (at $37^{\circ} \mathrm{C}$, for $3 \mathrm{~min}$ for HEPG-2, and $15 \mathrm{~min}$ for Caco-2 cells). Trypsin reaction was stopped with culture medium, cells were resuspended, counted (Neubauer chamber), diluted in culture media at a density of $10^{4}$ cells $/ \mathrm{mL}$, and seeded onto 96-well microplates.

MTT assay was used to evaluate cell viability. Briefly, cells were seeded in 96-well plates at a density of $10^{4}$ cells/well, and allowed to adhere for $24 \mathrm{~h}$ (HEPG-2 cells) and $96 \mathrm{~h}$ (Caco-2 cells), in an incubator at $37^{\circ} \mathrm{C}$ with an atmosphere containing $7 \% \mathrm{CO}_{2}$, in the growth medium previously described. After complete growth of the cells in the wells, the growth medium was replaced by the dispersions of $\beta$-carotene-loaded NLC, in the concentrations: 45.5, $22.75,11.38,5.69,2.84,1.42 \mu \mathrm{g} / \mathrm{ml}, 0.71$, and $0.36 \mu \mathrm{g} /$ $\mathrm{ml}$. Afterwards, the plates were mantained at $37^{\circ} \mathrm{C}$, $7 \% \mathrm{CO}_{2}$, for $48 \mathrm{~h}$. Afterwards, a volume of $11 \mu \mathrm{L}$ of MTT solution was added and incubated for $2 \mathrm{~h}$. Crystals were diluted with acid isopropanol and dye conversion was determined by absorbance measurement at $570 \mathrm{~nm}$ (Fluostar Optima, BMG Labtech, Ortenberg, Germany).

\section{Statistical analyses}

The statistical analyses were carried out using analysis of variance (ANOVA), followed by Tukey's test of average comparison $(p<0.05)$ and linear regression analysis. The data were analysed with the aid of the software SAS 9.2 (SAS Institute Corporation, Cary, NC).

\section{Results and discussion}

\section{Production and characterisation of $\beta$-carotene -loaded NLC}

Figure $1(\mathrm{~A})$ shows the curve conductivity vs. temperature, obtained to determine the phase inversion temperature, or $\mathrm{T}_{\mathrm{PIT}}$, of the murumuru butter NLC. 
(A)

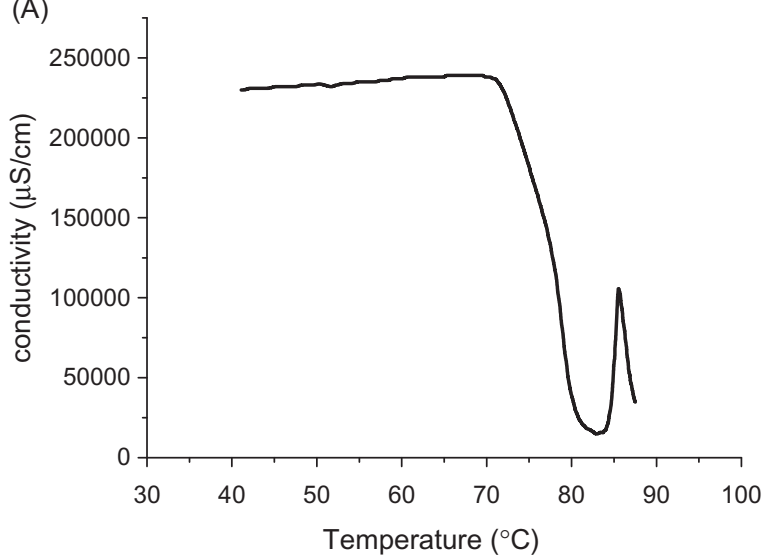

(B)

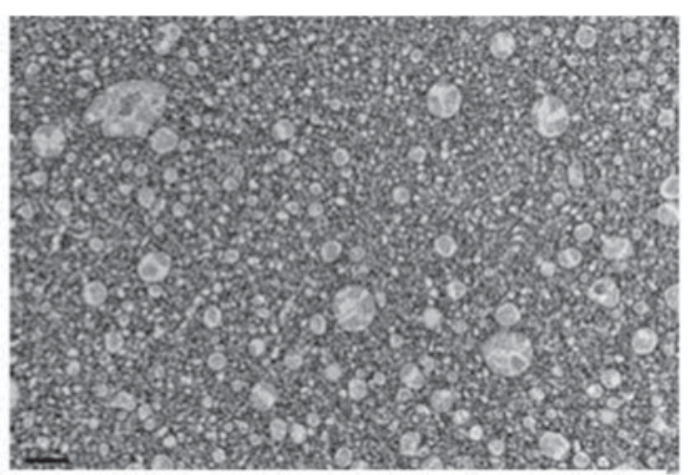

Figure 1. (A) Conductivity vs. temperature curve of the phase inversion of empty NLC produced with murumuru butter and the mixture Cremophor RH40 and Span 80 as surfactants. (B) Micrograph obtained by transmission electron microscopy of nanostructrured lipid carriers of murumuru butter (scale bar $=100 \mathrm{~nm}$ ).

Table 1. Average hydrodynamic diameter and polydispersity index of nanostructured lipid carriers of murumuru butter along the storage period.

\begin{tabular}{|c|c|c|c|c|}
\hline \multirow[b]{2}{*}{ NLC } & \multicolumn{2}{|c|}{ Fresh samples } & \multicolumn{2}{|c|}{ Day 120} \\
\hline & Average diameter $(\mathrm{nm})$ & PDI & Average diameter (nm) & PDI \\
\hline $\begin{array}{l}\beta \text {-carotene-loaded NLC } \\
\beta \text {-carotene-loaded NLC co-encapsulating } \alpha \text {-tocopherol }\end{array}$ & $\begin{array}{l}33.7 \pm 1.15^{\mathrm{a}} \\
33.4 \pm 0.81^{\mathrm{a}}\end{array}$ & $\begin{array}{l}0.21 \pm 0.02^{\mathrm{a}} \\
0.20 \pm 0.02^{\mathrm{a}}\end{array}$ & $\begin{array}{l}35.0 \pm 1.41^{\mathrm{a}} \\
34.4 \pm 1.02^{\mathrm{a}}\end{array}$ & $\begin{array}{l}0.27 \pm 0.02^{\mathrm{b}} \\
0.21 \pm 0.04^{\mathrm{a}}\end{array}$ \\
\hline
\end{tabular}

Average values \pm SD obtained from measurements of three dispersion samples.

Mean values followed by different lowercase letters in the same row are statistically different $(p<0.05)$ for the same parameter.

According to the data obtained in such curve, the value of $\mathrm{T}_{\mathrm{PIT}}$ was $77.5^{\circ} \mathrm{C}$. The curve also shows a peak of conductivity after phase inversion, typical of systems in which there are liquid crystalline and bicontinuous phases, and frequently associated with the formation of nanoparticles or nanoemulsions (Anton et al. 2008). The same authors also stated these peaks of conductivity can appear in systems with high concentrations of surfactant - more than $\asymp 9 \%$ in mass, which is the case of the system here investigated. These authors also explained that several types of structures (liquid crystalline structures) can be formed as temperature of the dispersions increases, such as lamellar phases, as well as bicontinuous microemulsions (Winsor III or Winsor IV systems). The different geometries of the phases formed during phase inversion can presumably create conductive channels between the electrodes of the conductivimeter, leading to an apparent temperature increase (Anton et al. 2008, Gomes et al. 2017).

Regarding the average size of the NLC produced, it did not change significantly when $\beta$-carotene was encapsulated. The average particle diameter of empty $\mathrm{NLC}$ was $37.7 \pm 1.9 \mathrm{~nm}$, whereas it was $33.7 \pm 0.9 \mathrm{~nm}$ for $\beta$-carotene-loaded NLC, and $33.4 \pm 0.4 \mathrm{~nm}$ for NLC co-encapsulating $\beta$-carotene and $\alpha$-tocopherol. Figure 1 (B) shows a micrograph obtained by transmission electron microscopy of the non-loaded NLC.

As for the stability of NLC over storage, the average NLC sizes (based on the intensity measurements obtained by photon correlation spectrometry) were in the range $33-35 \mathrm{~nm}$. They indicated that nanocarriers were highly stable during the storage period in terms of hydrodynamic diameter and particle size distribution. The low values of polydispersity indexes (PDI), around 0.20 , are also an indication of the high stability of NLC in terms of particle size. Such high stability can be due to the very reduced average size of the particles (lower than $40 \mathrm{~nm}$ ). Table 1 summarises the data about average hydrodynamic size and polydispersity index.

Regarding stability of the encapsulated $\beta$-carotene, it was significantly influenced by the presence of the co-encapsulated $\alpha$-tocopherol. Approximately $73 \%$ of the initial mass of $\beta$-carotene was preserved in the NLC with $\alpha$-tocopherol after 120 days. In contrast, NLC without $\alpha$-tocopherol protected $\beta$-carotene in a much lesser extent: in these nanocarriers, only $34 \%$ of the initial amount of $\beta$-carotene was preserved after 120 days of storage. As for the $\alpha$-tocopherol-loaded 
NLC, at the end of storage period, $76 \%$ of the initial amount was still present. However, it is important to notice that the percentage of preserved beta-carotene after the emulsification process (initial amount of beta-carotene added to the lipid phase before the production of solid lipid microparticles compared to the beta-carotene quantified in the NLC) was low (around 15\% for both NLCs). Regarding alpha-tocopherol, the correspondent value was around $60 \%$ for both lipid nanoparticles.

As for the stability of the encapsulated $\beta$-carotene in murumuru butter, NLC can be compared with other data from previous studies on nanoemulsions and solid lipid nanoparticles encapsulating $\beta$-carotene. Similarly to our results, the requirement of the coencapsulation with an antioxidant to protect encapsulated $\beta$-carotene has been also emphasised in other studies (Hentschel et al. 2008, Bovi et al. 2017, BritoOliveira et al. 2017, Gomes et al. 2017). Particularly, there is the study about characterisation of lipid nanoparticles of cupuacu (Theobroma grandiflorum) butter encapsulating $\beta$-carotene (Gomes et al. 2017), also produced by PIT. In the referred study, the need of $\alpha$-tocopherol was also noticed, but the effect it caused was not in terms of increasing the amount of remaining carotenoid at the end of storage period, but only a delay in the degradation of the bioactive. In that case, the percentage of remaining $\beta$-carotene at the end of 120 days was the same for the lipid nanoparticles with and without $\alpha$-tocopherol, differently from the present study, as previously reported. Such a difference is likely due to the type of butter used. Gomes et al. (2017) produced lipid nanoparticles with cupuacu butter, which is rich in stearic and oleic acids, whereas murumuru butter is a lauric oil, rich in $\mathrm{C} 12$ chains (about 50\%). The similarity of the hydrocarbon of the lipid core and surfactant chains are known to highly influence the packing of the particle interface. Tanaka et al. (2003) state that the more similar the chains, the more intense the interpenetration of the hydrophobic surfactant portion in the lipid core, and, therefore, the more firmly packed would be the interface. Firmly packed interfaces can delay the penetration of oxidant agents in the lipid core of particles, which could not have acted so efficiently in the present study as in Gomes et al. (2017), in which the surfactant chains (stearic and oleic) were more similar to the lipid chains of cupuacu butter. However, it is also important to notice that the lower similarity among the surfactant chains and murumuru butter fatty acids (52\% lauric acid) was not strong enough to lead to a high extent of destabilisation of the NLC (in terms of particle size), in comparison to the NLC of cupuacu butter (Gomes et al. 2017).

\section{Evaluation of in vitro dynamic digestibility of lipid nanocarriers and bioaccessibility of $\beta$-carotene}

Due to the fact they were more efficient to preserve encapsulated $\beta$-carotene, only NLC co-encapsulating $\alpha$-tocopherol were submitted to dynamic in vitro digestibility. Figure 2 shows the visual aspect of the fluids collected at the beginning of the digestion process and after each digestion step, as specified.
(A)

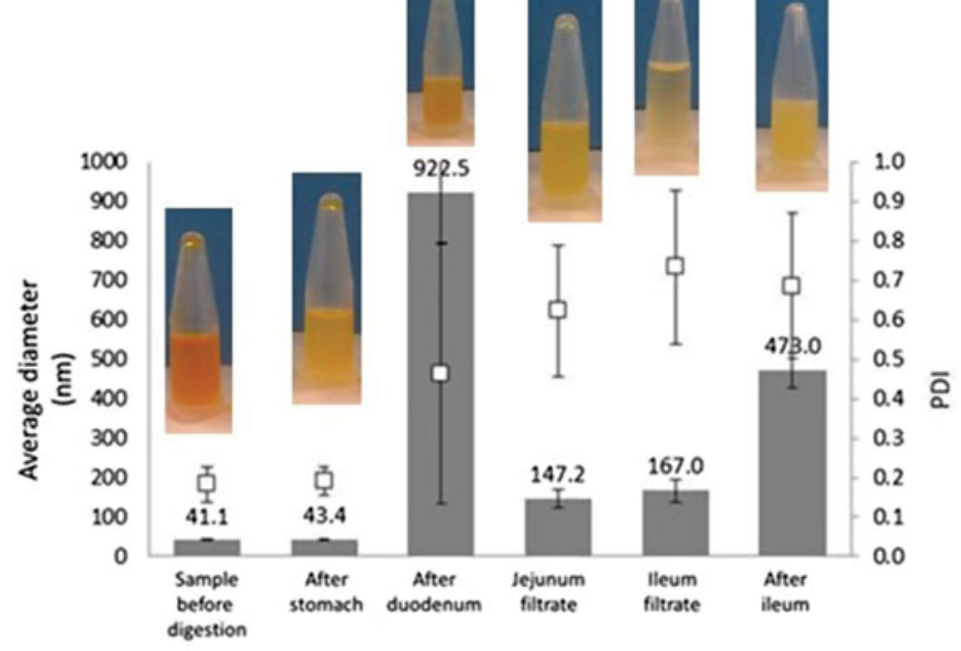

(B)

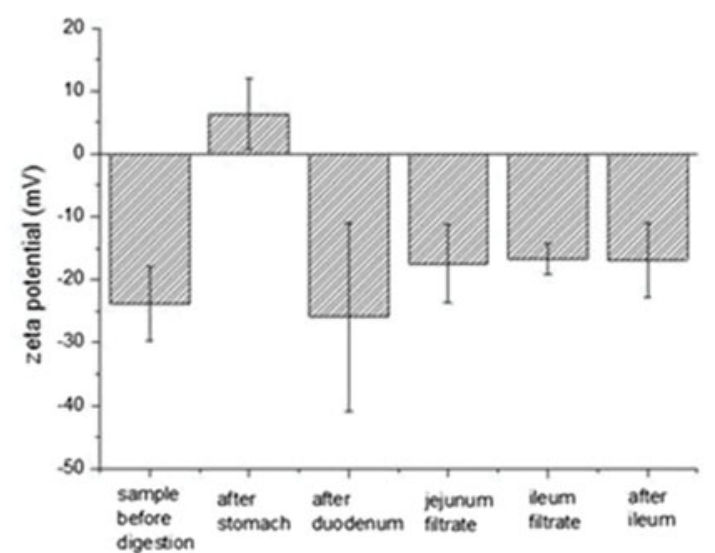

Figure 2. Average particle size and zeta potential in the steps of in vitro dynamic digestion of murumuru butter NLC coencapsulating $\beta$-carotene and $\alpha$-tocopherol: (A) average particle size (columns), polidispersity ( $\square$ ), and visual aspects (B) zeta potential. (The values and SD were obtained by the average of measurements obtained by the equipment, for samples obtained from a digestion complete experiment). 

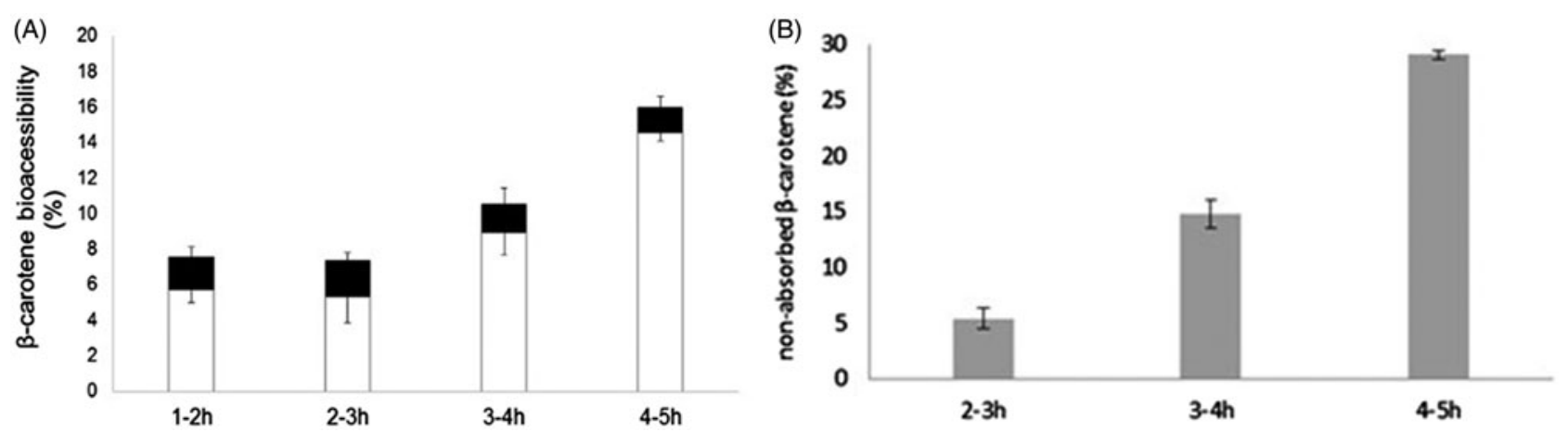

Figure 3. (A) Bioaccessibility of $\beta$-carotene along the digestion in the dynamic in vitro system: ( $\square$ ) jejunum filtrate and ( $\square$ ) ileum filtrate; (B) non-absorbed (or non-bioacessible) $\beta$-carotene. (The values and SD were obtained by the average of measurements obtained by the equipment, for samples obtained from a digestion complete experiment).

The change in the colour intensity after each digestion step is due to the dilution by the simulated gastric and intestinal fluids. It is also possible to notice that there is still beta-carotene non-absorbed after the end of ileum, and it is related to the quantification of bioaccessible and non-bioaccessible fractions which will be shown at the end of this section.

Regarding the values of average diameters and zeta potential in the different digestion steps, they are also shown in Figure 2. The data indicated there were no significant changes in the value of average diameter of NLC after stomach step, indicating they can be considered as highly resistant to the very acid gastric conditions, or gastro-resistant. As $\beta$-carotene is supposed to be absorbed in the small intestine, such resistance can be considered as a very important characteristic. As expected, zeta potential highly increased in the stomach, probably due to the changes in conditions of ionic strength and $\mathrm{pH}$, which may have led to the adsorption of gastric electrolytes on the polar heads of surfactants (Hur et al. 2009). On the other hand, zeta potential values observed after the duodenal step were negative, probably due to the displacement of surfactant molecules by surface-active molecules involved in the digestion, as lipase, bile salts and released fatty acids. Adsorption of negatively charged ions present in the intestinal fluid may also have contributed to the negative charge of NLC in this digestion step (Tokle et al. 2012).

The bioaccessibility percentages in duodenum, jejunum, and ileum were calculated and the values are in Figure 3. Percentages were calculated in relation to the initial amount of carotenoid present in murumuru butter NLC. Quantified by the carotenoid amount, total bioaccessible $\beta$-carotene was $42 \%$, being $35 \%$ in the jejunum filtrate and $7 \%$ in the ileum filtrate. Another fact is that the bioaccessibility of $\beta$-carotene was systematically higher in the jejunum filtrate compared to the ileal filtrate, and can be related to the release of fatty acids in each compartment of intestine, according to Figure 3. The jejunum filtrate contained $37.5 \%$ released fatty acids, whereas the ileum filtrate had $12.3 \%(49.8 \%$ as a total) at the end of digestion. Such data makes sense, as bioaccessibility and lipolysis are directly proportional (the higher the amount of fatty acids released, the higher the micellization of $\beta$-carotene in the corresponding digestion step).

It is also possible to compare the results of bioaccessibility and fatty acid release of murumuru and the data obtained by Gomes et al. (2017), using cupuacu butter NLC, also produced by PIT method and with similar average size. As a whole, the total bioaccessibility of $\beta$-carotene was very similar for both nanoparticles. However, the use of a dynamic in vitro system allowed to notice that the jejunum filtrate for murumuru butter NLC contained a higher concentration of $\beta$-carotene than the jejunum filtrate for cupuacu butter, as well as a higher released amount of free fatty acids. Such a result is probably due to the fact that murumuru butter contains more medium chain triglycerides than cupuacu butter, and they are hydrolysed faster than long-chain triglycerides (Sek et al. 2002). However, such a fact did not influence the value of total $\beta$-carotene bioaccessibility, which was $44.6 \%$ for cupuacu butter NLC. The difference was only that, apparently, murumuru butter was hydrolysed faster in the jejunum step.

\section{Evaluation of Caco-2 and HEPG cells viability}

The dependence of the cell viability according to nanoparticle concentration, for both types of cells tested, is shown in Figure 4. 


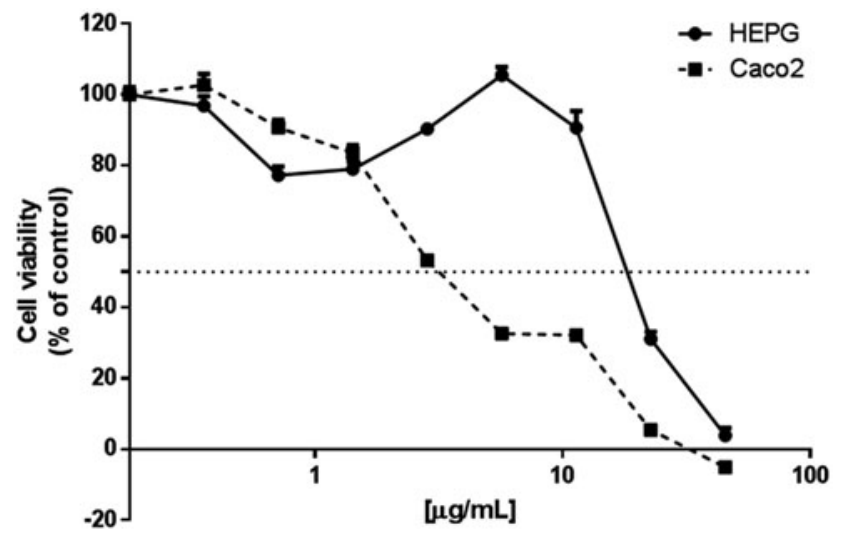

Figure 4. Cell viability (Caco-2 ( $\boldsymbol{\Delta})$ and HEPG ( $\boldsymbol{\square}$ ) cells) at different concentrations of $\beta$-carotene-loaded lipid nanocarriers co-encapsulating $\alpha$-tocopherol, after $48 \mathrm{~h}$ exposure as measured by MTT assay (average values \pm SD obtained from measurements of three samples).

According to data shown in Figure 4, Caco-2 cells were much more sensitive than HEPG cells to the presence of murumuru butter NLC. Some hypotheses can be placed considering data about the effects of surfactants on the Caco- 2 viability. Regarding nonionic surfactants, some of them are known to inhibit efflux transporters. Several studies indicate these surfactants, including Cremophor RH40 and Span 80, can inhibit membrane efflux transporters as P-glycoprotein (Pgp) (Rege et al. 2002). Such inhibition has the potential to increase oral absorption of certain drugs, as it delays their back transport to the apical surface of the tissue (Hugger et al. 2002). The cytotoxicity of lipids, surfactants, or mixture of both can alter the integrity of Caco-2 monolayer which causes increases in drug permeation but provides an undesired toxicity.

However, the cited studies were carried out with dispersions of surfactants, not with surfactants adsorbed on the interface of droplets or particles. Therefore, it is difficult to compare our data with data from the literature. In addition to the cited inhibition effect, the surfactants may also cause profound effects on cells, disturbing plasma membranes or removing their lipids (Hugger et al. 2002; Kiss et al. 2013). Apparently, the concentration of Cremophor RH40 present in the NLC was much lower than its CMC (critical micellar concentration) value $(0.01 \% \mathrm{~m} / \mathrm{v}$, Matsaridou et al. 2012), which may have led to the effect of inhibition of Pgp efflux transporters. Such inhibition is due to a mechanism of cell membrane fluidisation, which may have led to an easier permeation of the nanoparticles in the cell, due to the extremely reduced particle size. Such internalisation may have caused more intense cell damage, as NLC accumulated. The decrease in size leads to a highly significant increase of the surface area, which makes the surface of the nanomaterial to interact more intensively with the environment surrounding it, including cells. Increased absorption of nanoparticles in certain tissues may lead to their accumulation, which in turn may interfere with the critical biological functions of these cells (Aillon et al. 2009). It is difficult to compare the results obtained with data from the literature, as similar studies with such small NLC were not found. Generally, the average particle sizes of NLCs used in cytotoxicity studies are higher than $200 \mathrm{~nm}$. However, Li et al. (2016) evaluated the size-exclusive effect of NLC on permeability in Caco-2 cells, and observed that $100 \mathrm{~nm}$ particles showed higher permeability than 200 and $300 \mathrm{~nm}$ particles. Therefore, as our NLC presented an average size around $35 \mathrm{~nm}$, it is reasonable to consider they would permeate even more easily through the cell tissue, despite the fact that they were produced with a different composition from NLC tested by Li et al. (2016).

Such an effect was much less pronounced in HEPG cells, which can be seen by the values of $I C_{50}$. Whereas the $I C_{50}$ of CaCo-2 cells was $3.12 \mu \mathrm{g} / \mathrm{mL}$, for HEPG it was $20 \mu \mathrm{g} / \mathrm{mL}$. Doktorovova et al. (2014) listed several cytotoxicity studies performed with solid lipid nanoparticles and NLC, but only very few evaluated HEPG cells. However, it is clear that the values of $I C_{50}$ determined by the cited authors, for both types of cells, were much lower than the values typically found in the present study, although it must be considered the type of lipid, surfactants, and the average particle size were totally distinct than the other studies (Vighi et al. 2013, Severino et al. 2014).

It must be considered, though, that the material which will be in contact with the cells after ingestion will not be the intact NLC, even considering they were resistant to gastric conditions. As NLC will be digested in the gastrointestinal tract, and incorporated into the mixed micelles, the structures formed during their digestion in the small intestine is the material which will be in contact with cells. In the case of HEPG strain, which are liver cells, they will be in contact with the material which will be absorbed by the intestinal cells. In addition, we consider this material still deserves to be tested for food applications, due to the reasons given above and also because the NLC would be incorporated in a food matrix. So, the food matrix would also change the dynamics of the digestion process, and maybe the NLC will not present such a high toxicity as they presented in this study. 
Therefore, the cytotoxicity of the NLC need to be more deeply and detailed investigated, and one must be aware the results will depend on the case studied.

\section{Conclusions}

It was possible to conclude that nanostructuring of murumuru butter by phase inversion temperature method was possible, and the NLC were able to protect $\beta$-carotene, although a co-encapsulated antioxidant ( $\alpha$-tocopherol) was required for that. However, the high losses of $\beta$-carotene and $\alpha$-tocopherol in the nanoemulsification processes have to be considered and improvements need to be taken into consideration in the next studies.

Regarding cell viability studies, the results indicated the combination of non-ionic surfactants with NLC with much reduced average size can lead to a high level of cytotoxicity, even when food-grade ingredients are employed. These results reveal that the murumuru butter produced in this study can potentially be used in the controlled release of bioactives, but more detailed studies of cell toxicity must be performed.

\section{Disclosure statement}

No potential conflict of interest was reported by the authors.

\section{Funding}

The authors thank FAPESP (São Paulo State Research Foundation, Brazil) for the fellowships [grants 2010/20523-0, 2011/01260-0 and 2012/18495-3, for Graziela V.L. Gomes and Mirella R. Sola]. The work was also been supported by the Portuguese Foundation for Science and Technology (FCT) under the scope of the strategic funding of UID/BIO/ 04469/2013 unit and COMPETE 2020 [POCI-01-0145-FEDER006684] and BioTecNorte operation [NORTE-01-0145-FEDER000004] funded by the European Regional Development Fund under the scope of Norte2020 - Programa Operacional Regional do Norte.

\section{References}

Aillon, K.L., et al., 2009. Effects of nanomaterial physicochemical properties on in vivo toxicity. Advanced drug delivery reviews, 61 (6), 457-466.

Anton, N., and Benoit, J.P., Saulnier P., 2008. Design and production of nanoparticles formulated from nano-emulsion templates-a review. Journal of controlled release, 128, 85-199.

Anton, N. and Vandamme, T.F., 2009. The universality of low-energy nano-emulsification. International journal of pharmaceutics, 377 (1-2), 142-147.
Bertram, J.S. and Vine, A.L., 2005. Cancer prevention by retinoids and carotenoids: independent action on a common target. Biochimica et biophysica acta, 1740, 170-178.

Bonnaire, L.S., et al., 2008. Influence of lipid physical state on the in vitro digestibility of emulsified lipids. Journal of agricultural and food chemistry, 56 (10), 3791-3797.

Borrin, T.R., et al., 2018. Technological and sensory evaluation of pineapple ice creams incorporated with curcumin-loaded nanoemulsions obtained by the emulsion inversion point method. International journal of dairy technology, 71 (2), 491-500.

Bovi, G.G., Petrus, R.R., and Pinho, S.C., 2017. Production and physicochemical characterization of buriti (Mauritia flexuosa L.) oil nanoemulsions and feasibility of incorporation in isotonic sports drink. International journal of food science and technology, 52 (10), 2201-2209.

Brito-Oliveira, T.C., et al., 2017. Encapsulation of betacarotene in solid lipid microparticles stabilized with hydrolyzed soy protein isolate: production parameters, influence of alpha-tocopherol coencapsulation and stability under stress conditions. Journal of food science, 82 (3), 659-669.

Cao-Hoang, L., Fougere, R., and Wache, Y., 2010. Increase in stability and change in supramolecular structure of betacarotene through encapsulation into polylactic acid nanoparticles. Food chemistry, 24, 42-49.

Ciappellano, S.C., et al., 2016. In vitro toxicity assessment of oral nanocarriers. Advanced drug delivery reviews, $106(\mathrm{Pt}$ B), 381-401.

Cornacchia, L. and Roos, Y.H., 2011. Stability of $\beta$-carotene in protein-stabilized oil-in-water delivery systems. Journal of agricultural and food chemistry, 59 (13), 7013-7702.

de Carli, C., Moraes-Lovison, M., and Pinho, S.C., 2018. Production, physicochemical stability of quercetin-loaded nanoemulsions and evaluation of antioxidant activity in spreadable chicken pâtés. LWT - food science and technology, 98, 154-161.

Doktorovova, S., Souto, E.B., and Silva, A.M., 2014. Nanotoxicology applied to solid lipid nanoparticles and nanostructured lipid carriers - a systematic review of in vitro data. European journal of pharmaceuticals and biopharmaceuticals, 87 (1), 1-18.

Fraser, P.D. and Bramley, P.M., 2004. The biosynthesis and nutritional uses of carotenoids. Progress in lipid research, 43 (3), 228-265.

Gao, S. and McClements, D.J., 2016. Formation and stability of solid lipid nanoparticles fabricated using phase inversion temperature method. Colloids and surfaces A: physicochemical and engineering aspects, 499, 79-87.

Gomes, G.V.L., et al., 2017. Physico-chemical stability and in vitro digestion of beta-carotene-loaded lipid nanoparticles of cupuacu butter (Theobroma grandiflorum) produced by phase inversion temperature (PIT) method. Journal of food engineering, 192, 93-102.

Guerra, A., et al., 2012. Relevance and challenges in modeling human gastric and small intestinal digestion. Trends in biotechnology, 30 (11), 591-600.

Gupta, A., et al., 2016. Nanoemulsions: formation, properties and applications. Soft matter, 12 (11), 2826-2841.

Hentschel, A., et al., 2008. $\beta$-Carotene-loaded nanostructured lipid carriers. Journal of food science, 73, 1-6.

Hugger, E.D., et al., 2002. A comparison of commonly used polyethoxylated pharmaceutical excipients on their ability 
to inhibit P-glycoprotein activity in vitro. Journal of pharmaceutical sciences, 91 (9), 1991-2001.

Hur, S.J., Decker, E.A., and McClements, D.J., 2009. Influence of initial emulsifier type on microstructural changes occurring in emulsified lipids during in vitro digestion. Food chemistry, 114 (1), 253-262.

Kiss, L., et al., 2013. Kinetic analysis of the toxicity of pharmaceutical excipients Cremophor EL and $\mathrm{RH} 40$ on endothelial and epithelial cells. Journal of pharmaceutical sciences, 102 (4), 1173-1181.

Komaiko, J. and McClements, D.J., 2015. Low-energy formation of edible nanoemulsions by spontaneous emulsification: factors influencing particle size. Journal of food engineering, 146, 122-128.

$\mathrm{Li}, \mathrm{H}$. , et al., 2016. Size-exclusive effect of nanostructured lipid carriers on oral drug delivery. International journal of pharmaceutics, 511 (1), 524-537.

Loh, J.W., et al., 2010. Uptake and cytotoxicity of chitosan nanoparticles in human liver cells. Toxicology and applied pharmacology, 249 (2), 148-157.

Mambrim, M.C.T. and Barrera-Arellano, D., 1997. Caracterización de aceites de frutos de palmeras de la región amazónica del Brasil. Grasas y aceites, 48, 154-158.

Matsaridou, I., et al., 2012. The influence of surfactant HLB and oil/surfactant ratio on the formation and properties of self-emulsifying pellets and microemulsion reconstitution. AAPS PharmSciTech, 13 (4), 1319-1330.

McClements, D.J. and Rao, J., 2011. Food-grade nanoemulsions: formulation, fabrication, properties, performance, biological fate, and potential toxicity. Critical reviews in food science and nutrition, 51 (4), 285-330.

Ménard, O. et al., 2014. Validation of a new in vitro dynamic system to simulate infant digestion. Food chemistry, 145, 1039-1045.

Montenegro, L., et al., 2012. Idebenone-loaded solid lipid nanoparticles for drug delivery to the skin: in vitro evaluation. International journal of pharmaceutics, 434 (1-2), 169-174.

Müller, R.H., Mäder, K., and Gohla, S., 2000. Solid lipid nanoparticles (SLN) for controlled drug delivery - a review of the state of the art. European journal of pharmaceutics and biopharmaceutics, 50 (1), 161-177.

Pan, Y., Tikekar, R.V., and Nitin, N., 2016. Distribution of a model bioactive within solid lipid nanoparticles and nanostructured lipid carriers influences its loading efficiency and oxidative stability. International journal of pharmaceutics, 511 (1), 322-330.

Pinheiro, A.C., Coimbra, M.A., and Vicente, A.A., 2016. In vitro behaviour of curcumin nanoemulsions stabilized by biopolymer emulsifiers - effect of interfacial composition. Food hydrocolloids, 52, 460-467.

Pinho, S. C., de Carli, C., and Moraes-Lovison, M., 2018. Nanoemulsions produced by low energy methods: fundamentals and food applications. In: Rai R, Aswathanarayan JB, eds. Nanotechnology applications in the food industry. 1st ed. Boca Raton: CRC Press, 221-236.

Rege, B.D., Kao, J.P.Y., and Polli, J.E., 2002. Effects of nonionic surfactants on membrane transporters in Caco-2 monolayers. International journal of pharmaceutical sciences, 16, 237-246.

Reis, P.M., et al., 2008. Influence of surfactants on lipase fat digestion in a model gastro-intestinal system. Food biophysics, 3 (4), 370-381.

Relkin, P. and Shukat, R., 2012. Food protein aggregates as vitamin-matrix carriers: impact of processing conditions. Food chemistry, 134 (4), 2141-2148.

Salvia-Trujillo, L., et al., 2013. Modulating $\beta$-carotene bioaccessibility by controlling oil composition and concentration in edible nanoemulsions. Food chemistry, 39, 878-884.

Sek, L., et al., 2002. Evaluation of the in-vitro digestion profiles of long and medium chain glycerides and the phase behaviour of their lipolytic products. Journal of pharmacy and pharmacology, 54 (1), 29-41.

Severino, P., et al., 2014. Solid lipid nanoparticles for hydrophilic biotech drugs: optimization and cell viability studies (Caco-2 and HEPG-2 cell lines). European journal of medicinal chemistry, 81, 28-34.

Shinoda, K. and Saito, H., 1968. The effect of temperature on the phase equilibria and the types of dispersions of the ternary system composed of water, cyclohexane, and nonionic surfactant. Journal of colloid and interface science, 26 (1), 70-74

Tanaka, M., et al., 2003. Evidence for interpenetration of core triglycerides into surface phospholipid monolayers in lipid emulsions. Langmuir, 19 (13), 5192-5196.

Tikekar, R.V. and Nitin, N., 2011. Effect of physical state (solid vs. liquid) of lipid core on the rate of transport of oxygen and free radicals in solid lipid nanoparticles and emulsion. Soft matter, 7 (18), 8149-8158.

Tokle, T., et al., 2012. Impact of dietary fiber coatings on behavior of protein-stabilized lipid droplets under simulated gastrointestinal conditions. Food and function, 3 (1), 58-66.

Vighi, E., et al., 2013. Design flexibility influencing the in vitro behavior of cationic SLN as a nonviral gene vector. International journal of pharmaceutics, 440 (2), 161-169. 